\title{
Meningkatkan Integritas Remaja Berbasis Sertifikasi BNSP Penyuluh Antikorupsi Bersama LSP P3 Pembangun Penyuluh Integritas Bangsa
}

\author{
Dewi Puspaningtyas Faeni ${ }^{1 *}$, Ratih Puspitaningtias Faeni ${ }^{2}$, \\ Retno Fuji Oktaviani ${ }^{3}$, Ravindra Safitra Hidayat ${ }^{4}$ \\ ${ }^{1234}$ Fakultas Ekonomi dan Bisnis-Universitas Budi Luhur \\ Author E-mail: dewifaeni@budiluhur.ac.id
}

\begin{abstract}
A B S T R A K
Beberapa preseden hukum terlibat kasus korupsi yang melibatkan petinggi negara telah terjadi dan ini bukan merupakan peristiwa pertama. Hal ini terus berlanjut karena lemahnya aparat hukum, pola budaya kerja yang ada, pendidikan mengenai korupsi yang belum memadai dan rendahnya pengetahuan masyarakat perihal pencegahan korupsi. Pengabdian Kepada Masyarakat (PKM) ini bertujuan memberikan pembekalan bagi generasi muda dengan ilmu pencegahan korupsi dengan proses yang konstruktif yaitu pengujian Sertifikasi BNSP (Badan Nasional Sertifikasi Profesi) sebagai Penyuluh Antikorupsi yang memiliki legitimasi hukum. Responden atau Asesi yang dilibatkan adalah 100 (seratus) orang di lingkungan Kampus-kampus di Provinsi DKI Jakarta dalam periode Juni 2020 hingga Mei 2021. Proses Sertifikasi BNSP ini melibatkan LSP (Lembaga Sertifikasi Profesi) P3 Pembangun Penyuluh Integritas Bangsa (LSP P3 PIB) memakan waktu sekitar 4 (empat) bulan. Diawali dari proses Orientasi Umum, dilanjutkan dengan proses Orientasi Tehnis, proses pemberkasan, Pra Asesmen, lalu diakhiri dengan proses Uji Kompetensi yang keseluruhan prosesi didampingi oleh Narasumber dan para Asesor dari LSP P3 PIB. Kesimpulan dari kegiatan PKM ini adalah, para responden dalam hal ini Asesi sangat menjiwai semua proses hingga didapatkan Kompetensi 90\% dari keseluruhan Asesi.
\end{abstract}

Kata Kunci: Pendidikan Antikorupsi, LSP P3 PIB, Sertifikasi BNSP, Penyuluh Antikorupsi.

\section{A B S T R A C T}

The legal precedent involving state officials is not the first event, but rather occurs because of the weak legal apparatus, the pattern of existing work culture, inadequate education on corruption and low public knowledge regarding the prevention of corruption. Community Service (PKM) aims to provide education for the younger generation with the objective mainly prevention of corruption with a constructive process that is assessments of the BNSP Certification (National Professional Certification Agency) as an Anticorruption Extension that has legal legitimacy. Respondents or assessments involved are 100 (one hundred) people in the campuses in the Jakarta province in the period of June 2020 to May 2021. This BNSP Certification Process involves LSP (Professional Certification Body) P3 National Integrity Extension Builder (LSP P3 PIB) in circa 4 (four) months completed. Starting from the General Orientation 
with the Competency Test process which the whole procession was accompanied by assessment subject and assessors from LSP P3 PIB. The conclusion of this PKM activity is, the respondents in this case the Assessment strongly animates all processes until obtained competency $90 \%$ of the overall Assessment.

Key word: Anticorruption Education, LSP P3 PIB, BNSP Certification, Anticorruption Extension, Patriotism.

Copyright $(\subseteq 2021$ Authors. This is an open access article distributed under the Creative Commons Attribution License, which permits unrestricted use, distribution, and reproduction in any medium, provided the original work is properly cited.

\section{LATAR BELAKANG}

Pada tahun 2021 Indeks Persepsi Korupsi Indonesia berada pada peringkat 102 setelah meluncur tajam dari peringkat 85 di tahun 2019. Survei mengindikasikan, bahwa Indonesia berada pada zona darurat korupsi. Survei resmi dilakukan di 180 negara oleh Transparency International pada kurun waktu Juni 2019 hingga Juni 2020. Survei ini dilakukan setiap tahun dengan responden masyarakat pengguna jasa layanan publik atas dasar variabel-varibel yang berada di dalam tata laksana perusahaan atau Good Corporate Governance (GCG) terhadap para pejabat publik di kantor layanan publik. Dari sebuah survei yang dilakukan, ada 1842 terdakwa koruptor selama 2001 hingga 2019, telah terindikasi terjadi kerugian keuangan negara pada kurun waktu 2001-2019 sebesar 189,9 Trilyun Rupiah. Data yang dapat dilansir adalah hanya 15,09 Trilyun Rupiah yang dapat ditarik kembali sebagai hukuman finansial sebesar $8,9 \%$ dari total kerugian keuangan negara yang telah menguap dan tentunya menjadi biaya yang harus ditanggung bangsa dan negara. Berarti dalam hal ini negara telah dirugikan sebesar 153,1 Trilyun Rupiah (Rimawan, 2019).

Tahun ini Indonesia disejajarkan dengan negara seperti Gambia. Ironismya pelaksanaan survei diumumkan pada tiga bulan sebelum terjadinya dua peristiwa operasi tangkap tangan dua pejabat teras di dua kementerian strategis di republik ini dan hanya beberapa hari sebelum Hari Anti Korupsi Sedunia. Sebuah fakta yang memprihatinkan, disaat Indonesia bergulat dengan keterpurukan ekonomi yang diakibatkan oleh pandemi, besarnya lautan putus hubungan kerja (PHK), serta di tengah besarnya kebutuhan keuangan negara untuk bantuan sosial bagi bangsa Indonesia yang terdampak pandemi, justru para petinggi departemen-departemen strategis malah terjaring tindak pidana korupsi.

Tentunya biaya ini dinamakan sebagai biaya sosial, biaya yang kelak ditanggung oleh masyarakat yang tentunya berdampak pada ekonomi biaya tinggi yang mengakibatkan harga pendidikan yang tidak terjangkau, menurunnya kualitas hidup masysrakat, karena tingginya bahan pangan pokok, tingginya biaya pajak, biaya berobat dan pengobatan yang semakin mencekik leher, serta banyaknya anak-anak balita yang terdampak stunting atau gagal tumbuh karena buruknya gizi, serta tingginya jumlah wanita meninggal saat melahirkan serta tingginya jumlah pengangguran di usia produktif.

Berdasarkan hasil analisis kondisi tersebut, maka dilakukanlah pemetaan se-bagai berikut. Ekonomi biaya tinggi yang dipicu oleh besarnya kerugian keuangan negara berdampak sangat luas dan masif, karena survei ICP (International Corruption Index) atau Indeks Persepi Korupsi (IPK) yang dilakukan oleh Transparansi Inter-nasional menempatkan Indonesia pada peringkat 102 dari 180 negara yang disurvei, yaitu setara dengan negara selevel Gambia. Peringkat ini merosot dari IPK tahun 2019 yaitu pada peringkat 85 merosot menjadi peringkat 102. Aspek variabel yang disurvei adalah antara lain, tata laksana administrasi GCG (Good Corporate Governance) dari para pejabat publik mengenai penerapan tata laksana layanan publik. Keterpurukan peringkat Indonesia dari 
85 menjadi peringkat 102 menunjukkan bahwa Indonesia termasuk negara yang buruk dalam kualitas pelayanan publik terutama dalam penanganan perizinan serta pelayanan publik lainnya, serta ini menandakan masih terindikasi besarnya tindakan kejahatan ekonomi yang lebih dikenal sebagao tindak pidana korupsi (Transparansi Internasion-al, 2002).

Tindak pidana korupsi berasal dari sebuah kosa kata Latin corruptio dengan pengertian harfiah sesuatu yang busuk, sehingga tindak pidana korupsi merupakan perbuatan busuk, sehingga sangat tepat mengkategorikan korupsi sebagai sebuah keja-hatan luar biasa atau extraordinary crimes. Hal ini terjadi karena teori segitiga. Teori segitiga dimaksud adalah, adanya kesempatan, motivasi dan rasionalisasi (Cressey, 2018).

Pada beberapa kasus tindak pidana korupsi yang terjadi di Indonesia ada be-berapa pemicu, yaitu adanya kesempatan, budaya politik balas jasa, nepotisme, adanya eskalasi kebutuhan seseorang, adanya upaya memperkaya diri sendiri maupun kelompok serta beberapa kondisi lainnya (Hemahua, 2016).

Adanya sikap ketidak pedulian masyarakat serta rendahnya pengetahuan masyarakat perihal tindak pidana korupsi, dapat menjadi pemicu para koruptir yang dengan leluasa melakukan tindakan penyimpangan tanpa kontrol sosial. Untuk itu PKM pada ke-sempatan ini bertujuan untuk melakukan edukasi dan pembekalan secara berlegitimasi melalui program Sertifikasi BNSP (Badan Nasional Sertifikasi Profesi) sebagai Penyuluh Antikorupsi. Program ini menjadi upaya sistematis bagi aksi nyata pencegahan antikorupsi yang merupakan jawaban dari Teori Penyebab Korupsi Greed, Opportunity, Need, Expose (GONE) (Bologne, 2018).

Diharapkan Responden atau Asesi program ini, dapat membekali generasi muda dengan ilmu pengetahuan cara-cara pencegahan tindak pidana korupsi, dengan cara melakukan Sertifikasi BNSP Penyuluh Antikorupsi sebagai aksi nyata pembentukan agen-agen perubahan melalui peningkatan awareness di kalangan generasi muda. Ge-nerasi muda sebagsi Agent of Change diharapkan dapat meningkatkan kewaspadaan masyarakat dalam menjaga marwah bangsa yang menjunjung tinggi integritas dan tata nilai sebagai bangsa yang besar. Kelak sebagai pemegang sertifikat BNSP Penyuluh Antikorupsi, para Asesi ini berada di Garda Terdepan dalam mengawal Negara Kesatuan Republik Indonesia yang mencanangkan tahun 2045 mencapai Indonesia Emas sebagai negara berdaulat Bebas Korupsi.

Sertifikasi BNSP merupakan Lembaga Resmi berkekuatan hukum sebagai perpanjangan tangan dari Kementrian Ketanaga Kerjaan dengan mengeluarkan sertifikat lisensi kepada LSP P3 PIB untuk melakukan proses sertifikasi Penyuluh Antikorupsi dengan tujuan memberdayakan generasi muda untuk lebih meningkatkan wawasan kebangsaan dan memiliki kesadaran untuk berpartisipasi aktif dalam pembangunan. Kontribusi generasi muda dalam hal ini para Asesi diharapkan dapat menumbuhkembangkan semangat perlawanan terhadap Tindak Pidana Korupsi (SKKNI 303, 2016).

Profil dari Asesi adalah mahasiswa-mahasiswi di lingkungan Provinsi DKI Jakarta, yang tengah menyelesaikan studi pendidikan Strata 1, terutama mereka yang tengah mengambil mata kuliah Etika Bisnis dan Profesi serta Good Corporate Governance (GCG). Mata kuliah ini bermuara pada akar ilmu etika bisnis dalam menjalankan profesi. Asesi tengah mengambil mata kuliah pada Semester pertengahan, yang mempersiapkan mereka untuk memasuki dunia kerja. Profil Asesi dalam PKM ini adalah dengan batasan usia antara 19 hingga 24 tahun. Berdomisili di Indonesia dan memiliki wawasan kebangsaan yang minim. Hal ini terjadi mengingat Asesi memiliki latar belakang yang beragam dan dibesarkan di dalam iklim pendidikan Barat yaitu rata-rata lulusan Sekolah Menengah Atas Swasta Internasional, sehingga sebagian tidak melalui pendidikan moral Pancasila dan budi pekerti. 
Tabel 1. Demografis Asesi Berdasarkan Gender

\begin{tabular}{llcc}
\hline \multirow{2}{*}{ Responden/Asesi } & Lokasi & \multicolumn{2}{c}{ Jumlah } \\
\cline { 3 - 4 } & & Pria & Wanita \\
\hline Siswa-siswi S1 & Tempat Uji Kompetensi & 38 & 12 \\
Semester Ganjil & LSP P3 PIB & & \\
\hline Siswa-siswi S1 & Tempat Uji Kompetensi & 41 & 9 \\
Semester Genap & LSP P3 PIB & & \\
\hline
\end{tabular}

Sumber: Data Primer, 2021

\section{RUMUSAN MASALAH MITRA}

Berdasarkan hasil indentifikasi permasalahan dari para Asesi, latar belakang pendidikan ratarata dari Sekolah Menangah Atas Swasta Asing atau Internasional, berbahasa bilingual, tidak memiliki latar belakang pendidikan dengan ilmu dasar Moral Pancasila dan Budi Pekerti, serta terjebak dalam pergaulan hedonisme, sehingga rasa kebangsaan para Asesi belum mencerminkan pribadi yang Nasionalis. Para Asesi juga merasa tidak memiliki rasa ketertarikan dalam membangun Negara, ada rasa kurang peduli terhadap apa yang terjadi dengan Negara, terutama semua yang berkaitan dengan tindak Pidana Korupsi. Sikap skeptis dan masa bodoh ini yang mendorong PKM wajib dilakukan di Kampus lingkungan Provinsi DKI Jakarta.

Tabel 2. Data Permasalahan Asesi

\begin{tabular}{ll}
\hline No & \multicolumn{1}{c}{ Permasalahan } \\
\hline 1 & Tidak peduli terhadap korupsi \\
\hline 2 & Tidak peduli terhadap politik maupun kondisi negara \\
\hline 3 & $\begin{array}{l}\text { Kurang berminat terhadap perkembangan ekonomi } \\
\text { negara }\end{array}$ \\
\hline 4 & Hilang rasa kepedulian sesame \\
\hline 5 & Tidak bangga menjadi orang Indonesia \\
\hline 6 & Cenderung tidak peka terhadap lingkungan \\
\hline 7 & Tidak merasa penting membenahi negara \\
\hline 8 & Rasa kebangsaan yang tipis \\
\hline 10 & Tidak hafal hari-hari penting nasional \\
\hline 11 & $\begin{array}{l}\text { Tokoh yang diidolakan adalah artis K-Pop atau Rapper } \\
\text { luar negeri }\end{array}$ \\
\hline 12 & Merasa malu mengaku sebagai orang Indonesia \\
\hline 13 & Tidak ingin tinggal di Indonesia \\
\hline 14 & Tipisnya nilai-nilai religi \\
\hline 15 & Mayoritas agnostik dan tidak percaya Tuhan \\
\hline
\end{tabular}

Sumber: Hasil survei, April 2021

\section{Solusi yang Ditawarkan}

Berdasarkan hasil kesepakatan dengan para Asesi, maka para asesi akan dilibatkan pada suatu program sertifikasi BNSP yang sarat dengan aktivitas kebangsan dan penambahan kebangsaan untuk bekal mereka bekerja dan memberikan solusi untuk meningkatkan wawasan kebangsaan dengan jati diri sebagai warga negara Indonesia dengan menerapkan Penyuluh Antikorupsi berdasarkan Standar Kompetensi Kerja Nasional Indonesia 303 tahun 2016 sebagai berikut:

Secara terstruktur semua permasalahan akan diberikan solusinya melalui unit kompetensi yang telah dijabarkan di atas. Secara terperinci tabel berikut menggambarkan solusi yang ditawarkan untuk menyelesaikan masalah.

Target luaran dalam kegiatan Pengabdian Kepada Masyarakat (PKM) ini sebagai berikut:

1. Terbentuk Penyuluh Antikorupsi .

2. Tertatanya mentalitas yang memiliki rasa kebangsaan.

3. Meningkatkan kepekaan lingkungan.

4. Meningkatkan rasa kewarganegaraan yang tinggi.

5. Meningkatkan kepedulian yang tinggi.

6. Meningkatkan kepekaan terhadap kondisi keuangan negara.

7. Meningkatkan rasa kebangsaan.

8. Membangun rasa memiliki dan jiwa bela negara.

9. Terbangun jiwa yang memiliki wawasan kebangsaan yang tinggi

10. Percaya diri sebagai Penyuluh Antikorupsi

11. Memiliki daya pengaruh yang tinggi terhadap terhadap lingkungannya

12. Artikel ilmiah dalam jurnal, dipublikasi melalui media online.

\section{METODE PELAKSANAAN}

Pendidikan Penyuluh Antikorupsi memiliki daya ungkit dan peranan yang sangat menentukan kepekaan lingkungan para Asesi sebagai seorang mahasiswa. Kepekaan sebagai warga negara yang baik akan muncul di saat para Asesi sibuk mengumpulkan berkas-berkas sebagai dokumen wajib. Untuk itu diperlukan penguatan ego strengthening melalui tahapan sistematika sebagai tertera pada Gambar 1. dan Gambar 2. 
Tabel 3. Unit Kompetensi Sertifikasi BNSP Penyuluh Antikorupsi

\begin{tabular}{lll}
\hline No & Unit Kompetensi & \\
\hline 1 & M.74PAK01.001.1 & Mengaktualisasikan Nilai-Nilai Integritas \\
\hline 2 & M-74PAK01.002.1 & Menangani Konfllk yang Muncul dalam Proses Penyuluhan Antikorupsi \\
\hline 3 & M.74PAK01.003.1 & Menerapkan Aspek K-3 dalam Pelaksaanan Penyuluhan Antikorupsi \\
\hline 4 & M.74PAK01.004.1 & Menumbuhkan Semangat Perlawanan terhadap Korupsi \\
\hline 5 & M-74PAK01.005.1 & Menyadarkan Bahaya dan Dampak Korupsi Termasuk Perilaku Koruptlf, Kolusi, dan Nepotisme \\
\hline 6 & M-74PAK01.006.1 & Membangun Cara Berpikir Kritis terhadap Masalah Korupsi \\
\hline 7 & M.74PAK01.007.1 & Meningkatkan Pengetahuan Terkait Antikorupsi \\
\hline 8 & M-74PAK01.008.1 & Meningkatkan Keterampilan Antikorupsi \\
\hline 9 & M.74PAK01.009.1 & Membangun Sikap Antikorupsi \\
\hline 10 & M.74PAK01.010.1 & Menumbuhkembangkan Kelembangaan Antikorupsi \\
\hline 11 & M.74PAK01.011.1 & Mendorong Kemandirian Kelompok Sasaran \\
\hline 12 & M/74PAK01.012.1 & Menumbuhkan Pelaku Utama Antikorupsi \\
\hline 13 & M.74PAK01.013.1 & Mengorganisasikan Kelompok Sasaran \\
\hline 14 & M.74PAK01.014.1 & Membangun Komunikasi Kelompok Sasaran Penyuluhan \\
\hline 15. & M.74PAK01.015.1 & Menumbuhkan Jejaring Kerja Antara Kelompok Sasaran \\
\hline 16 & M.74PAK01.016.1 & Melakukan Kolaborasi \\
\hline 17 & M.74PAK01.017.1 & Memobillsasi Gerakan Antikorupsi \\
\hline 18 & M.74PAK01.018.1 & Pelaksanaan Penyuluhan Antikorupsi \\
\hline 19 & M.74PAK01.019.1 & Memantau Pelaksanaan Penyuluhan Antikorupsi \\
\hline 20 & M.74PAK01.020.1 & Memfasilitasi Penguatan Kapasitas Kelembagaan dan Kelompok \\
\hline
\end{tabular}

Sumber: Departemen Tenaga Kerja, 2016

Tabel 4. Solusi Yang Ditawarkan Dalam Menyelesaikan Permasalahan Mitra

\begin{tabular}{|c|c|c|}
\hline No & Uraian & Unit Kompetensi \\
\hline 1 & Minim informasi mengenai Tindak Pidana Korupsi & Unit Kompetensi 1 \\
\hline 2 & Tidak peduli terhadap kemiskinan & Unit Kompetensi 2 \\
\hline 3 & Kurang berminat perihal terjadinya ekonomi biaya tinggi & Unit Kompetensi 3 \\
\hline 4 & Rasa kebangsaan yang rendah & Unit Kompetensi 4 \\
\hline 5 & Tidak memiliki rasa bangga sebagai orang Indonesia & Unit Kompetensi 5 \\
\hline 6 & Tidak memiliki kepekaan sosial & Unit Kompetensi 6 \\
\hline 7 & Tidak merasa penting membenahi negara & Unit Kompetensi 7 \\
\hline 8 & Rasa kebangsaan yang tipis & Unit Kompetensi 8 \\
\hline 9 & Lebih respek terhadap artis Korea dan sejenis & Unit Kompetensi 9 \\
\hline 10 & Tidak mengenal pahlawan & Unit Kompetensi 10 \\
\hline 11 & Tokoh yang diidolakan adalah artis K-Pop atau Rapper luar negeri & Unit Kompetensi 11 \\
\hline 12 & Merasa tidak hebat kalau mengaku orang Indonesia & Unit Kompetensi 12 \\
\hline 13 & Tidak ingin tinggal di Indonesia & Unit Kompetensi 13, 14 \\
\hline 14 & Tipisnya nilai-nilai religi & Unit Kompetensi 15, 16 \\
\hline 15. & Mayoritas agnostik dan tidak percaya Tuhan & Unit Kompetensi 17,18 \\
\hline 16 & Kurang mengenal nama dan jasa para pahlawan & Unit Kompetensi 19 \\
\hline 17 & Tidak hafal Pancasila & Unit Kompetensi 20 \\
\hline
\end{tabular}

Sumber: Data Primer, 2021 
Gambar 1. Flow Proses Sertifikasi Penyuluh Antikorupsi

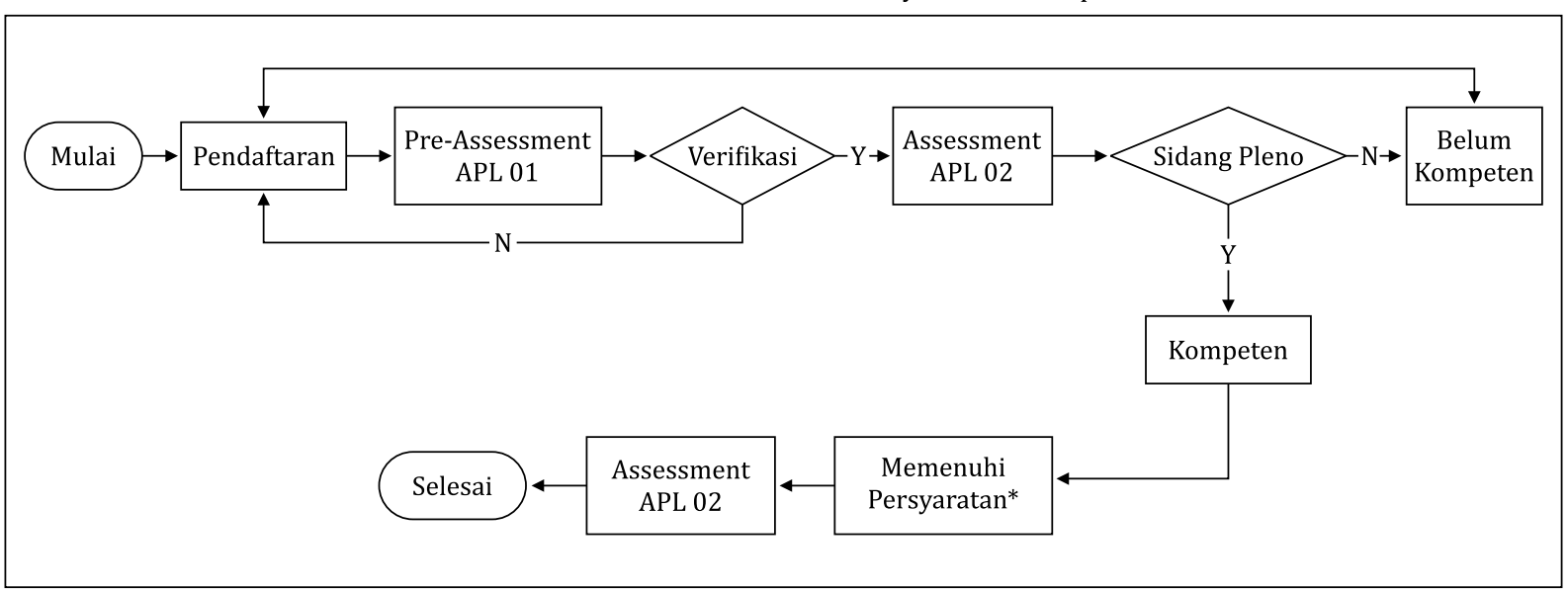

Sumber: LSP P3 PIB, 2021

Program ini diawali dengan penjelasan SKKNI dan SKEMA yang disampaikan pada saat Orientasi Tehnis dan Orientasi Umum, lalu dilanjutkan dengan pengisian Formulir APL-01 dan APL-02 setelah itu diverifikasi dan divalidasi pada tahapan Pra Asesmen dilakukan oleh Admin LSP P3 PIB. Dilanjutkan kemudian dengan proses Asesmen dilaksanakan dengan tahap Uji Kompetensi atau Uji Portofolio dengan Asesor yang sudah ditunjuk dari LSP P3 PIB.
Pada tabel 5 di bawah ini dijelaskan jadwal dan tahapan proses sertifikasi BNSP Penyuluh Antikorupsi yang diselenggarakan oleh LSP P3 PIB bagi para Asesi. Semua proses dan tahapan dilakukan sesuai dengan jadwal pada table di bawah.

\section{HASIL DAN PEMBAHASAN}

Program dijalankan sesuai langkah-langkah yang telah dijabarkan di atas. Dalam pelaksanaannya

Tabel 5. Jadwal dan Tahapan Sistematika Proses Sertifikasi

\begin{tabular}{|c|c|c|c|}
\hline HARI & KEGIATAN & MATERI & KETERANGAN \\
\hline 1 & $\begin{array}{c}\text { Orientasi } \\
\text { \& } \\
\text { Pre-Assessment } 01\end{array}$ & $\begin{array}{l}\text { Pembukaan } \\
\text { Orientasi Pengenalan Program } \\
\text { Manfaat } \\
\text { Tujuan } \\
\text { Tata Laksana } \\
\text { Pasil Akhir } \\
\text { Pengisian Form Apl-01 } \\
\text { Bimtek via WA Group } \\
\text { Melengkapi Data-Data }\end{array}$ & $\begin{array}{l}\text { Opening Speech Oleh Direktur Utama LSP P3 PIB } \\
\text { Pemaparan Program } \\
\text { Awereness Tentang Pentingnya Sertifikasi. } \\
\text { Kick Off Wa Bimtek Group } \\
\text { Pemberian Google Drive } \\
\text { Tata Cara Pengisian dan Upload Form ApI O1 Dan Apl O2, Regulasi, Informasi Tahapan } \\
\text { Penyelesaian Dokumen. } \\
\text { 1. Merancane Kebijakan Integritas Organisasi } \\
\text { 2. Melaksanakan Program Integritas Organisasi } \\
\text { 3. Melakukan Penilaian Risiko Korupsi } \\
\text { 4. Memantau Pelaksanaan Rencana Mitigasi Risiko Korupsi }\end{array}$ \\
\hline 2 & Pre-Assessment 02 & $\begin{array}{l}\text { Pengisian Apl-02 } \\
\text { Bimtek via WA Group }\end{array}$ & $\begin{array}{l}\text { Unit Kompetensi } \\
\text { 5. Melakukan Pemeriksaan Pelanggaran Terhadap Kebijakan Integritas Organisasi } \\
\text { 6. Memantau Tindak Lanjut Rekomendasi Perbaikan Terhadap Kebijakan Integritas } \\
\text { 7. Memantau Sistem Integritas Organisasi } \\
\text { 8. Mengevaluasi Sistem Integritas Organi sasi }\end{array}$ \\
\hline 3 & Assessment & Zoom Assessment & Assessment - Pengecekan Portofclio dan Wawancara \\
\hline 4 & Rapat Pleno Asesor & Pembahasan Hasil Ujian Asesmen & $\begin{array}{l}\text { Rapat pembahasan hasil ujian para Asesi vang dihadiri secara Quorum oleh para Asesor Penguji } \\
\text { dan Dewan Pengambil Keputusan sebagai tahapan Penjaminan Mutu. Tahapan Ini merupakan } \\
\text { tahapan akhir finalisasi pernyataan tentang keputusan kelulusan } \\
======\rightarrow \text { (Kompeten / Belum Kompeten ) }\end{array}$ \\
\hline 5 & Pengumuman Kelulusan & Kompeten / Belum Kompeten (Asesi) & $\begin{array}{l}\text { Tahapan Finalisasi dari hasil sidang rapat pleno yang menyatakan kelulusan kepada Para Asesi } \\
====-\rightarrow \text { (Kompeten / Belum Kompeten) }\end{array}$ \\
\hline 6 & Pendistribusian Sertifikat & Pembagian Sertifikat Kompeten & Penyerahan Sertifikat Sebagai Simbolisasi Kelulusan \\
\hline
\end{tabular}

Sumber: LSP P3 PIB, 2021 
ditemukan beberapa kendala sebagai berikut:

\section{Permasalahan pada saat Penerapan PKM}

1. Belum tersosialisasinya isu korupsi, membuat sulit untuk melakukan diseminasi kepada para Asesi.

2. Minimnya pengetahuan mengenai korupsi menjadi tantangan psikologis tersendiri.

3. Keterbatasan literatur mengenai korupsi, menjadi hambatan tersendiri.

4. Proses pembelajaran dan pemberkasan yang panjang membuat Asesi merasa demotivasi.

5. Lingkungan masih memandang skeptis masalah pemberantasan korupsi.

Namun dari program penerapan unit kompetensi, beberapa masalah sudah dapat diselesaikan. Secara terperinci table di bawah menerangkan bagaimana tiap unit kompetensi menghasilkan solusi untuk permasalahan.
Kegiatan PKM semester Ganjil dan Genap Tahun Ajar 2020/2021 ini dimulai dari bulan November 2020 sampai dengan Mei 2021. Kegiatan dimulai dari pengamatan dan diskusi terkait gambaran mengenai permasalahan mitra masyarakat mengenai peningkatan wawasan kebangsaan, tata nilai, GCG dalam sistematika Sertifikasi BNSP untuk Profesi Penyuluh Antikorupsi. Kegiatan PKM ini dilaksanakan secara bertahap selama 4 bulan, mulai dari tahap persiapan hingga proses sertifikasi, sidang pleno, pembagian sertifikat hingga ke pelaporan.

Program ini diterapkan untuk mengetahui pengetahuan dan kesadaran para Asesi mengenai pentingnya menjaga negara ini dari perbuatan busuk, tindak pidana korupsi dalam pelanggaran 7 Delik yang tertuang pada UU 20/2001 yaitu pentingnya meningkatkan kompetensi sebagai

Tabel 6. Solusi dan Output Sertifikasi Penyuluh Antikorupsi

\begin{tabular}{|c|c|c|}
\hline No & Unit Kompetensi & Solusi \\
\hline 1 & Mengaktualisasikan Nilai-Nilai Integritas & Wawasan kebangsaan meningkat \\
\hline 2 & Menangani Konfllk yang Muncul dalam Proses Penyuluhan Antikorupsi & $\begin{array}{l}\text { Mampu meningkatkan kepekaan sosial dalam } \\
\text { menangani konflik sosial }\end{array}$ \\
\hline 3 & Menerapkan Aspek K-3 dalam Pelaksaanan Penyuluhan Antikorupsi & Kewaspadaan perihal Aspek K3 \\
\hline 4 & Menumbuhkan Semangat Perlawanan terhadap Korupsi & Menggugah wasasan kebangsaan \\
\hline 5 & $\begin{array}{l}\text { Menyadarkan Bahaya dan Dampak Korupsi Termasuk Perilaku Koruptlf, } \\
\text { Kolusi, dan Nepotisme }\end{array}$ & Menjadi lebih cerdas UU 20/2001 \\
\hline 6 & Membangun Cara Berpikir Kritis terhadap Masalah Korupsi & Membangun pola pikir kritis \\
\hline 7 & Meningkatkan Pengetahuan Terkait Antikorupsi & Merubah mentalitas menjadi lebih peka \\
\hline 8 & Meningkatkan Keterampilan Antikorupsi & Meningkatkan kemampuan menyuluh \\
\hline 9 & Membangun Sikap Antikorupsi & Mengetahui dasar UU 31/1999 \\
\hline 10 & Menumbuh kembangkan Kelembangaan Antikorupsi & $\begin{array}{l}\text { Membangun jejaring agar peka terhadap bahaya } \\
\text { laten korupsi }\end{array}$ \\
\hline 11 & Mendorong Kemandirian Kelompok Sasaran & Mendorong menjadi pribadi yang mandiri \\
\hline 12 & Menumbuhkan Pelaku Utama Antikorupsi & Tercetak jiwa heroik sebagai pelaku Antikorupsi \\
\hline 13 & Mengorganisasikan Kelompok Sasaran & Membangun kolaborasi kelompok \\
\hline 14 & Membangun Komunikasi Kelompok Sasaran Penyuluhan & Membuat jejaring komunikasi penyuluhan \\
\hline 15. & Menumbuhkan Jejaring Kerja Antara Kelompok Sasaran & Melakukan kerjasama jejaring \\
\hline 16 & Melakukan Kolaborasi & Kolaboratif tandem kelompok-kelompok \\
\hline 17 & Memobillsasi Gerakan Antikorupsi & Pembentukan kelompok dan sub kelompok \\
\hline 18 & Pelaksanaan Penyuluhan Antikorupsi & Realisasi rencana kerja \\
\hline 19 & Memantau Pelaksanaan Penyuluhan Antikorupsi & Evaluasi pelaksanaan \\
\hline 20 & Memfasilitasi Penguatan Kapasitas Kelembagaan dan Kelompok & Penyempurnaan kegiatan \\
\hline
\end{tabular}

Sumber: Data Primer, 2021 
Penyuluh Antikorupsi, agar mampu berperan aktif dalam mengawal demokrasi dan kesejahteraan bangsa Indonesia. Terutama dalam meningkatkan rasa cinta kasih ter-hadap bangsa sendiri serta peningkatan kemaslahatan serta kesejahteraan bangsa Indo-nesia, agar mampu hidup dalam kelayakan. PKM ini memiliki nilai tambah ekonomis dan para asesi dapat memperoleh Sertifikasi BNSP yang prestisius.

Berikut adalah tahapan-tahapan penerapan yang dilalui dalam program PKM ini:

1. Tahap Pertama

Pengumpulan Asesi dari berbagai Kampus di Provinsi DKI Jakarta, berdasarkan demografis usia, gender dan Indeks Persepsi Kumulatif sebagai dasar prestasi akademis.

2. Tahap Kedua

Orientasi Umum dan Orientasi Teknis yang menerangkan perihal Program Sertifikasi BNSP Penyuluh Antikorupsi.

3. Tahap Ketiga

Para Asesi diminta untuk mengisi Formulir APL-01 dan APL-02.

4. Tahap Empat

Tahapan Pra Asesmen yaitu saat Para Asesi dilakukan verifikasi Data dan validasi guna menentukan dapat tidaknya Asesi meneruskan program.

5. Tahapan Lima

Para Asesi diberikan Asesor yang menjadi pembimbing pemberkasan selama program sertifikasi berjalan.

6. Tahapan Enam

Para Asesi diminta untuk melengkapi seluruh dokumen dan data untuk tahapan Asesmen.

7. Tahapan Tujuh

Apabila Asesi sudah dinyatakan Valid dan memenuhi syarat, maka dapat diteruskan pada tahapan berikutnya yaitu Uji Kompetensi berupa Presentasi Aspek K3 (Keamanan, Kesehatan dan Keselamatan Kerja) serta Presentasi Materi Penyuluh Antikorupsi dan dilanjutkan dengan Uji Komprehensif.

8. Tahapan Delapan

Adalah tahapan dimana seorang Asesi dirapatkan berdasarkan hasil Uji Kompetensi dan Uji Komprehensif dalam sebuat Rapat
Pleno yang dihadiri 3/4 dari jumlah Quorum Asesor.

9. Tahapan Sembilan Pengumuman Hasil Rapat Pleno tentang hasil Kompetensi para Asesi.

10. Tahapan Sepuluh

Penyerahan Sertifikat BNSP.

Dalam bentuk gambar tahapan-tahapan tersebut dapat digambarkan sesuai gambar 2 yang tertera di bawah ini.

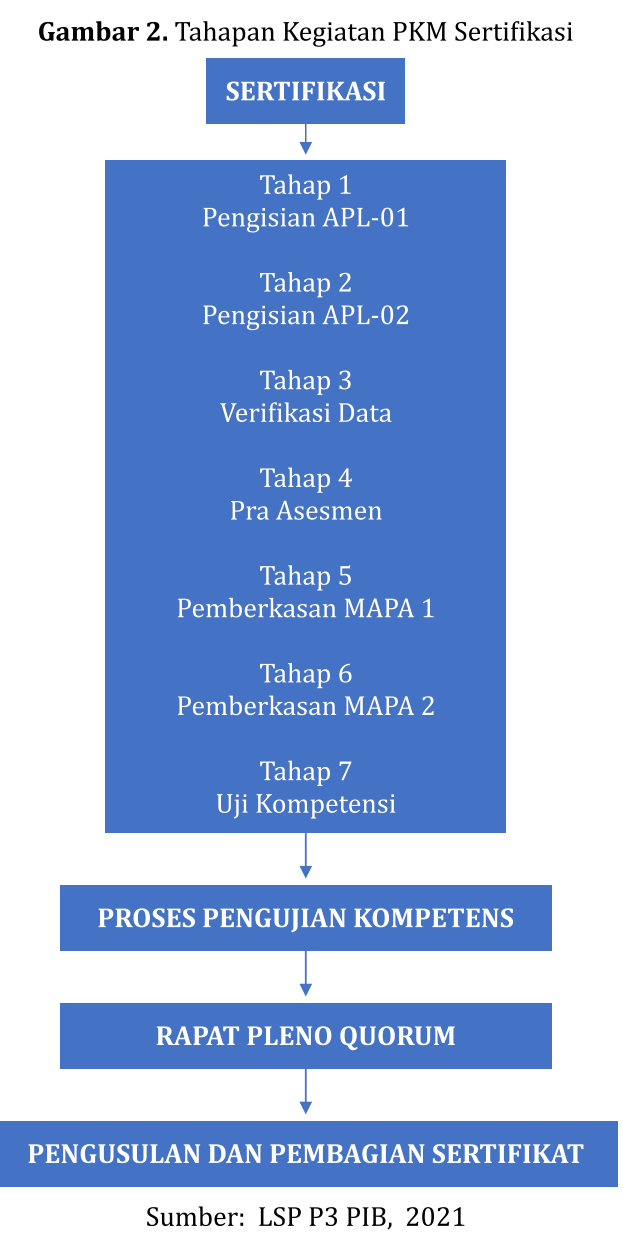

PKM ini juga dicanangkan untuk menghasilkan output yang meningkatkan gaung pengaruhnya ke masa mendatang. Berbagai target luaran dapat dilihat dalam tabel berikut ini.

\section{KESIMPULAN DAN SARAN}

Program berjalan dengan lancar meski menghadapi berbagai tantangan, namun dapat diatasi berdasarkan Langkah-langkah uji kompetensi yang telah dirancang untuk program sertifikasi ini. 
Tabel 7. Target Luaran

\begin{tabular}{lll}
\hline No & & \multicolumn{1}{c}{ Target Jenis Luaran } \\
\hline 1 & Publikasi Ilmiah & Publikasi Seminar Internasional di dalam negeri ber ISBN \\
\hline 2 & Publikasi prosiding seminar & International Conferene on Human Resources Management \\
\hline & internasional di dalam negeri & \\
\hline 3 & Publikasi di media massa electronic & Artikel di media massa \\
\hline 4 & Desiminasi Program Sertifikasi & Program Sertifikasi Penyuluh Antikorupsi BNSP dengan LSP P3 PIB keseluruh kampus \\
\hline & & di Indonesia \\
\hline
\end{tabular}

Sumber: Data diolah sendiri, 2021

\section{Kesimpulan}

Hasil penerapan program ini menunjukkan output yang positif, yang dijabarkan di bawah ini.

1. Berdasarkan laporan dan pengamatan terhadap kegiatan Pengabdian Kepada Masyarakat ini, maka terlihat bahwa program telah dilakukan dengan baik dan mendapat respon positif dari para Asesi.

2. Dari hasil observasi dan dokumentasi kegiatan berdasarkan pengamatan interview langsung kepada para asesi maka disimpulkan bahwa asesi menyadari bahwa Kegiatan Program Sertifikasi ini dirasakan penting dan wajib untuk memenuhi Indonesia Emas 2045.

\section{Saran}

Berdasarkan evaluasi yang telah dilakukan dapat diajukan beberapa saran sebagai berikut:

1. Waktu pelaksanaan kegiatan Pengabdian Kepada Masyarakat perlu ditambah agar tujuan kegiatan dapat tercapai sepenuhnya kepada khalayak sasaran yang berbedabeda.

2. Adanya kegiatan lanjutan yang berupa pelatihan peningkatan pengetahuan Antikorupsi secara periodik sehinga dapat meningkatkan kemampuan para Asesi dalam melaksanakan Penyuluhan Antikorupsi.

3. Program Sertifikasi BNSP Penyuluh Antikorupsi ini sangat bermanfaat, sehingga harus diadakan secara berkelanjutan dan terdiversifikasi untuk berbagai tingkatan pendidikan. Hal ini penting dilakukan agar tercipta banyak sekali Penyuluh Antikorupsi yang dapat menyiarkan pendidikan Antikorupsi dimulai dari tingkat pendidikan dasar hingga pendidikan tertinggi masyarakat.

4. Menjadi usulan sebagai mata kuliah kurikulum wajib di setiap kampus secara Nasional.

\section{Dokumentasi Kegiatan Sertifikasi}
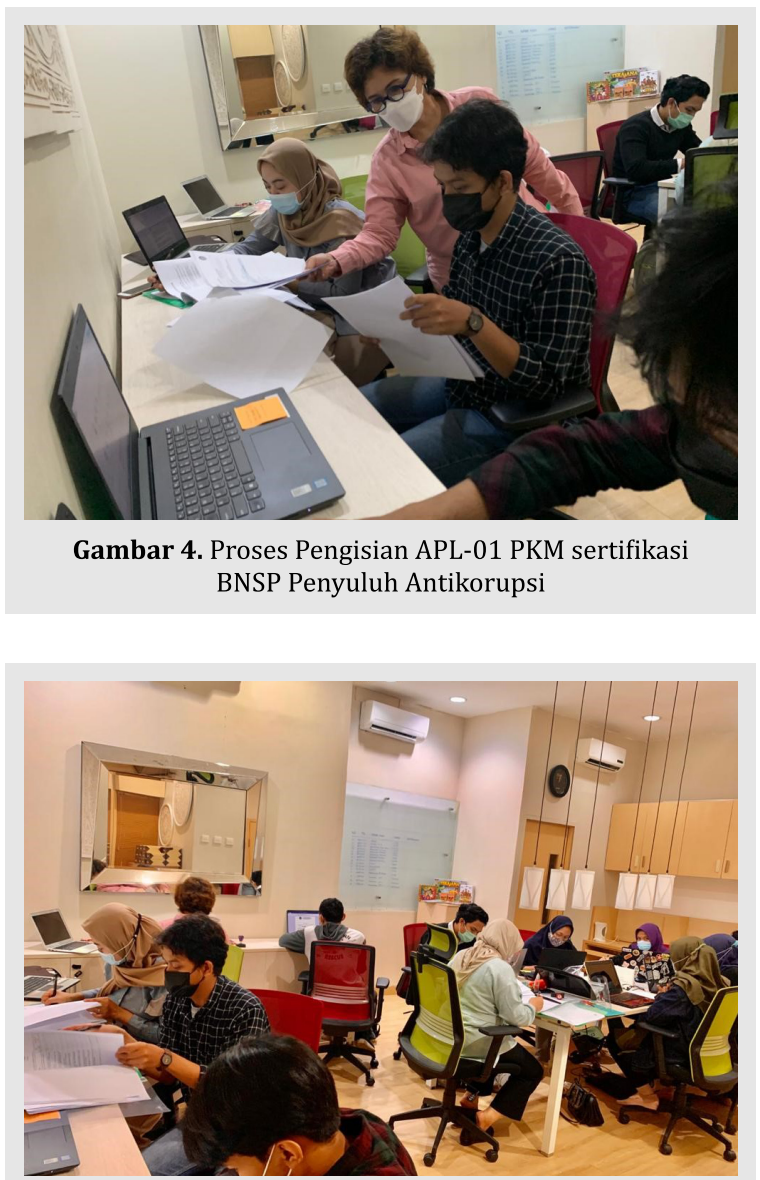

Gambar 5. Proses Pra Asesmen PKM sertifikasi BNSP Penyuluh Antikorupsi 

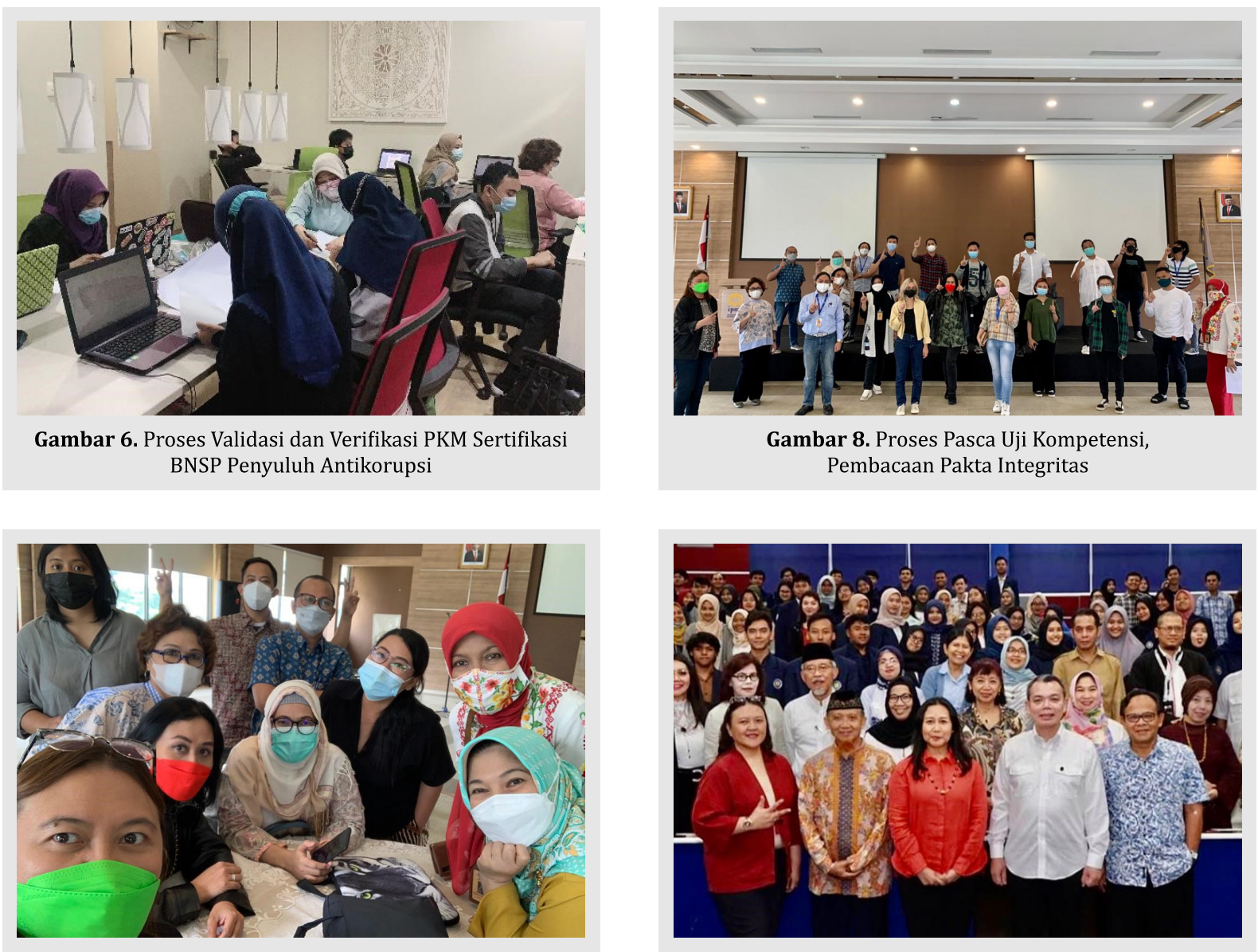

Gambar 7. Profil Para Asesor sedang beristirahat

Gambar 9. Foto Bersama Setelah Pelaksanaan Berakhir

\section{DAFTAR PUSTAKA}

BNSP. 2019. The Strategic Meeting of The Ad-Hoc Task Force. Majalah Sertifikasi Edisi Kedua.

Bologne, J. 2018. Handbook on Corporate Fraud: Prevention, detection, and investigation: ButterworthHeinemann. 10th Edition.

Cressey, D. 2018. Other People's Money; A Study In The Social Psychology Of Embezzlement. Glencoe, IL: Free Press. 15th Edition.

Klitgaard, Robert, 2019, Controlling Corruption. University of CaliBNSP, fornia Press. 12th Edition.

Klitgaard, Robert, 2000 Ronald Maclean-Abaroa, H. Lindsey Parris, Corrupt Cities, A Practical Guide to Cure and Prevention, Institute Contemporary Studies Oakland, California, World Bank Institute

Peraturan Badan Nasional Sertifikasi Profesi Nomor 2/BNSP/III/2014 tentang LSP (Lembaga Sertifikasi Profesi)

Standar Kompetensi Kerja Nasional Indonesia, 2016. No. 303 Penyuluh Antikorupsi - Keputusan Menteri Ketenagakerjaan Republik Indonesia Nomor 303 Tahun 2016 Ten-tang Penetapan Standar Kompetensi Kerja Nasional Indonesia Kategori Aktivitas Profesional, Ilmiah, Dan Teknis Golongan Pokok Aktivitas Profesional, Ilmiah, Dan Teknis Bidang Penyuluhan Pada Jabatan Kerja Penyuluh Antikorupsi

Transparency International, 2021. Research Index Corruption Perception Yearly Report.

Wolfe, David T. Dana R. Hermanson. 2004. The Fraud Diamond: Considering The Four Element of Fraud. CPA 


\section{LAMPIRAN 1}

\section{Peta Lokasi Tempat Uji Kompetensi \\ Program Sertifikasi BNSP}

\section{Tempat Uji Kompetensi LSP P3 PIB}

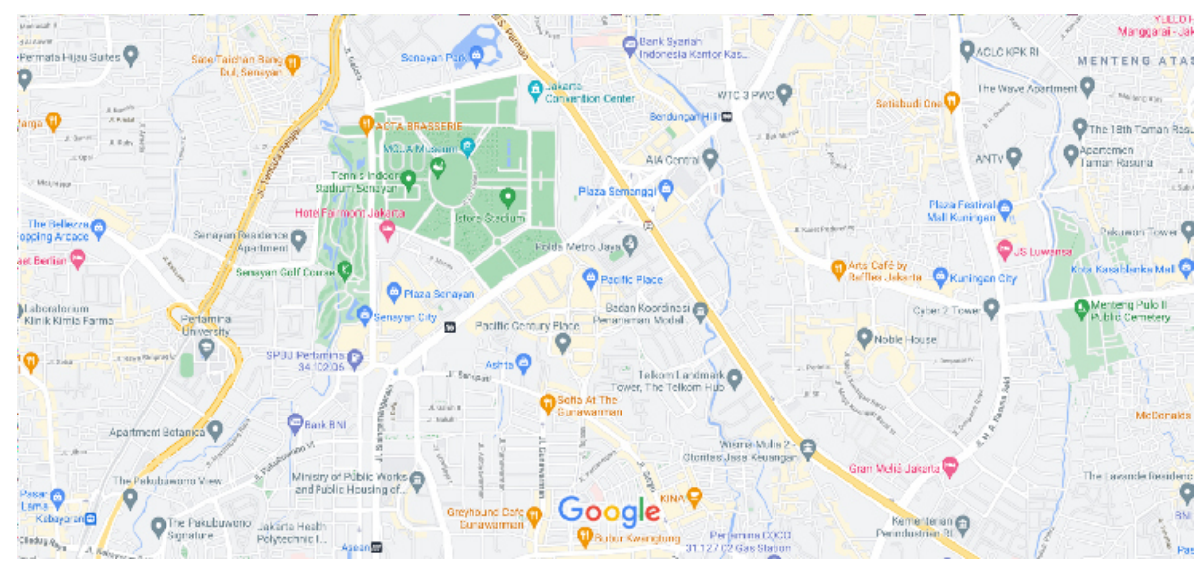

